\title{
DNA barcode reference libraryconstruction and population genetic diversity and structure analysis of Amomum villosum Lour. in Daodi production area
}

\section{Zhang Danchun ( $D$ 13570254463@139.com )}

China Medical College Hospital: China Medical University Hospital https://orcid.org/0000-0003-40450682

\section{Xiaoxia Ding}

2nd Clinical Medical College of Guangzhou University of Chinese Medicine: Guangdong Provincial Hospital of Traditional Chinese Medicine

\section{Wan Guan}

2nd Clinical Hospital of Guangzhou Chinese Traditional Medicine College: Guangdong Provincial Hospital of Traditional Chinese Medicine

\section{Juan Huang}

2nd Clinical Hospital of Guangzhou Chinese Traditional Medicine College: Guangdong Provincial Hospital of Traditional Chinese Medicine

He Su

2nd Clinical Hospital of Guangzhou Chinese Traditional Medicine College: Guangdong Provincial Hospital of Traditional Chinese Medicine

\section{Xiaohui Qiu}

Guangdong provincial key Laboratory of Clinical Research on Traditional Chinese Medicine Syndrome

\section{Zhi hai Huang}

2nd Clinical Hospital of Guangzhou Chinese Traditional Medicine College: Guangdong Provincial Hospital of Traditional Chinese Medicine

\section{Lu Gong}

2nd Clinical College of Guangzhou Unversity of Chinese medicine

\section{Research}

Keywords: A. villosum, molecular markers, DNA barcode, ISSR, genetic diversity

Posted Date: December 23rd, 2020

DOl: https://doi.org/10.21203/rs.3.rs-133546/v1 
License: (c) (i) This work is licensed under a Creative Commons Attribution 4.0 International License. Read Full License 


\section{Abstract}

Background: The Amomum villosum has the situation that it is inferior and other other varieties are used as $A$. villosum in the market. In order to develop and utilize the genuine medicinal materials $A$. villosum, this experiment aims to carry out the identification and research of variety of the $A$. villosum and analyze its genetic diversity, constructing the DNA barcode database of the genuine medicinal materials $A$. villosum in Guangdong Province and providing recommendations for populations planting, which will be critical to the further research of $A$. villosum. (2) Methods: A total of 141 samples of $A$. villosum were analyzed by DNA barcoding to construct DNA barcode database. The genetic diversity of $A$. villosum sampled from 7 populations in Guangdong Province was detected based on ISSR molecular marker technology. (3)

Results: The success rates of PCR amplification and sequencing of five barcodes of $A$. villosumwas rbcL> ITS $>$ ITS2 $>$ psbA-trnH $>$ matK. 141 samples of $A$. villosum from 7 populations in Guangdong Province were used to construct a reference DNA barcode database containing 531 sequences. The results of genetic diversity were as follow, the number of alleles Na ranged from 1.2879 to 1.7121 , the effective number of alleles Ne ranged from 1.1848 to 1.4240 , the gene diversity index $(\mathrm{H})$ ranged from 0.2536 to 0.1117 , and the Shannon index (I) ranged from 0.3816 to 0.1658 , whichindicatedthegenetic diversity of A. Villosum was rich. The total genetic diversity among the 7 populations $(\mathrm{Ht})$ was 0.3299 , the genetic diversity within the populations $(\mathrm{Hs})$ was 0.1819 , and the gene differentiation coefficient (Gst) was 0.4487 . AMOVA showed that the genetic variation within the populations and the genetic variation between the populations accounted for $68.74 \%(P<0.05)$ and $31.26 \%(P<0.05)$ respectively, indicating that the genetic variation of $A$. villosum was mainly within the populations. The gene flow $\mathrm{Nm}$ was 0.6143 .The genetic distance of the 7 populations was $0.0844-0.3347$, and the genetic identity was $0.7156-0.9191$, confirming that the genetic relationship of each population was relatively close. The 7 populations were significantly grouped in the cluster analysis and the genetic level of each population from high to low was as follow: ZY (National Highway Roadside) > ZJD (Zhongjiaodong) > GY (Geopark) >MM (Dianbai) > YC (Dadong Village) > XFC (Xingfu Village) > TK (Tankui Village). There was no correlation between the geographic distance and the degree of genetic differentiation among populations.

Conclusion: By amplifying and sequencing five barcodes of ITS2, psbA-trnH, ITS, matK and rbcL, a reference DNA barcode database of $A$. villosum with 531 sequences was constructed. The results of genetic diversity showed that it is necessary to take appropriate in situ protection measures for the populations of $A$. villosum in Yangchun City and increase the genetic exchange between populations to improve the genetic diversity of $A$. villosum.

\section{Introduction}

Amomum villosum Lour. is a medicinal plant of Zingiberaceae family mainly grown in southern China. It's ripe and dried fruit Fructus Amomi is the famous traditional Chinese medicine (TCM) with the effects of dampening appetite, warming the spleen to stop diarrhea, regulating qi and relieving the fetus and has 
been used for thousands of years. Modern pharmacological studies show that, Fructus Amomi has great activities of anti-ulceration, anti-diarrhea, anti-inflammatory and antimicrobial[1]. In addition, Fructus Amomi is also used in food, liquors, and tea as the health product and condiment. Yangchun Citylocated in Guangdong Provinceis considered the Daodi (genuine) production area of Fructus Amomi for its high quality. With the rapid development of the city as well as traditional Chinese medicine business, the habitat of $A$. villosum has been frequently destroyed that seriously threatened its germplasm resources. In 2016, Fructus Amomiwasselected as one of the eight legally protected TCM variety in Guangdong Province.

The genetic diversity of a species is the basis for its survival and evolution, which is of great significance tothe analysis of evolutionary polymorphism, genetic relationship, optimization of germplasm resources and protection of populations[2]. Polymerase Chain Reaction(PCR)-based molecular markers have been widely used in the analysis of plant genetic diversity[3]. Among them, Inter-Simple Sequence Repeat (ISSR) is a fast and efficient marker, with the characteristics of high polymorphism, high reliability, low cost, and does not require pre-determination of target sequence information[4, 5], which is widely used in germplasm identification and genetic diversity analysis[6]. Another marker, DNA barcodes, proposed in 2003 can not only be used in biological identification, but also in genetic diversity analysis[7] .

In the current study, ISSR and DNA barcoding markers were used to investigate the genetic diversity of seven populations of $A$. villosum in its Daodi production area, Yangchun City of Guangdong Province. Five barcodes ITS2, psbA-trnH, ITS, matK and $r b c L$ were amplified and DNA barcode reference libraries were constructed. This study will provide insights into the identification, conservation, domestication, and breeding of $A$. villosum.

\section{Results}

\subsection{DNA barcode reference library construction}

We extracted the genomic DNA from 141 samples of $A$. villosum. The OD260/280 was $1.76-1.98$ for all the DNA samples and the concentration was $73.70-1294.80 \mathrm{ng} / \mu \mathrm{L}$. Five DNA barcodes of all the samples were amplified and sequenced. The PCR amplification and sequencing results were shown in Table 1. It showed that the success rate of sequencing for each barcode wasrbcL $(100.00 \%)>$ ITS $(98.58 \%)>$ ITS2 $(95.04 \%)>p s b A-t r n H(53.90 \%)>$ matK $(29.08 \%)$. The ranking of the success rate of PCR amplification was consistent with that of sequencing. Thus, these sequences constructed the DNA barcode reference library of $A$. villosum in Guangdong Province. 
Table 1

DNA amplification and sequencing results of $A$. villosum

\begin{tabular}{|llll|}
\hline & sequence/ bar & PCR amplification success rate (\%) & sequencing success rate (\%) \\
\hline ITS2 & 134 & 95.74 & 95.04 \\
\hline psbA-trnH & 76 & 57.45 & 53.90 \\
\hline ITS & 139 & 99.29 & 98.58 \\
matK & 41 & 29.08 & 29.08 \\
\hline rbcL & 141 & 100.00 & 100.00 \\
\hline
\end{tabular}

We analyzed the sequences of each barcode we obtained. Sequence characterization for each barcodes was shown in Table 2. All the sequences of the five barcodes had no variation sites, showing a strong conservation. ITS2 had the shortest sequence length and the highest GC content. The sequences of each barcode were shown in Fig. 1 to Fig. 5 .

Table 2

Analysis of the sequences of DNA barcode of $A$. villosum

\begin{tabular}{|lllll|}
\hline & $\begin{array}{l}\text { average sequence length } \\
\text { /bp }\end{array}$ & $\begin{array}{l}\text { GC content } \\
\text { /\% }\end{array}$ & $\begin{array}{l}\text { conservative } \\
\text { sites }\end{array}$ & $\begin{array}{l}\text { variation site /Information } \\
\text { site }\end{array}$ \\
\hline ITS2 & 229 & 59.83 & 229 & 0 \\
\hline $\begin{array}{l}\text { psbA- } \\
\text { trnH }\end{array}$ & 667 & 28.49 & 667 & 0 \\
\hline ITS & 653 & 56.20 & 653 & 0 \\
\hline matK & 787 & 29.22 & 787 & 0 \\
\hline rbcL & 729 & 41.84 & 729 & 0 \\
\hline
\end{tabular}

\subsection{ISSR polymorphism and genetic diversity}

In the present study, ISSR-PCR fragments of $A$. villosum populations ranged from $300 \mathrm{bp}$ to $2000 \mathrm{bp}$. An example of amplified profiles was shown in FigueS1. The samples for ISSR analysis was shown in TableS1. A total of 66 ISSR bands were generated from 7 A. villosum populations by the selected 6 primers. Among them, 56 bands were polymorphic, thus the percentage of polymorphic bands was $84.85 \%$ for all the 7 A. villosum populations. For each primer, it amplified 6-14 bands with the polymorphic ratio was $64.29 \%-100.0 \%$. The results were shown in Table 3. 
Table 3

ISSR banding patterns of $7 \mathrm{~A}$. villosum populations.

\begin{tabular}{|c|c|c|c|c|c|}
\hline primers & sequences & $\operatorname{Tm}\left({ }^{\circ} \mathrm{C}\right)$ & amplification bands & polymorphic bands & PPB(\%) \\
\hline UBC808 & $(\mathrm{AG})_{8} \mathrm{C}$ & 52.00 & 11 & 11 & 100.00 \\
\hline UBC817 & $(\mathrm{CA})_{8} \mathrm{~A}$ & 49.24 & 11 & 10 & 90.91 \\
\hline UBC825 & $(A C)_{8} T$ & 52.00 & 12 & 12 & 100.00 \\
\hline UBC840 & $(\mathrm{GA})_{8} \mathrm{YT}$ & 52.74 & 12 & 10 & 83.33 \\
\hline UBC866 & $(\mathrm{CTC})_{6}$ & 56.60 & 6 & 4 & 66.67 \\
\hline UBC889 & $\mathrm{DBD}-(\mathrm{AC})_{7}$ & 46.83 & 14 & 9 & 64.29 \\
\hline \multicolumn{3}{|l|}{ sum } & 66 & 56 & 84.85 \\
\hline \multicolumn{3}{|l|}{ mean } & 11 & 9.33 & 84.82 \\
\hline \multicolumn{6}{|c|}{$\begin{array}{l}\text { Genetic diversity information of } A \text {. villosum populations analyzed by Popgene } 32 \text { was shown in } \\
\text { Table } 4 \text {. Among the populations of } A \text {. villosum, population } Z \text { Y had the highest genetic diversity (PPB }= \\
71.21 \%, \mathrm{Na}=1.7121, \mathrm{Ne}=1.4240, \mathrm{H}=0.2536, \mathrm{I}=0.3816) \text { while population TK had the lowest genetic } \\
\text { diversity }(\mathrm{PPB}=28.79 \%, \mathrm{Na}=1.2879, \mathrm{Ne}=1.1848, \mathrm{H}=0.1117, \mathrm{I}=0.1658 \text { ). At the species level, the } \\
\text { value of } \mathrm{Na}, \mathrm{Ne}, \mathrm{H}, \mathrm{I} \text { and } \mathrm{PPB} \text { were } 1.4834,1.3115,0.1820,0.2689 \text { and } 47.19 \text {, respectively. }\end{array}$} \\
\hline
\end{tabular}

Table 4

Genetic diversity of $A$. villosum

\begin{tabular}{|lllllll|}
\hline & NO. & Na & Ne & H & I & PPB(\%) \\
\hline ZJD & 5 & 1.5303 & 1.3492 & 0.1998 & 0.2954 & 53.03 \\
\hline TK & 4 & 1.2879 & 1.1848 & 0.1117 & 0.1658 & 28.79 \\
\hline ZY & 4 & 1.7121 & 1.4240 & 0.2536 & 0.3816 & 71.21 \\
\hline XFC & 7 & 1.4394 & 1.2685 & 0.1624 & 0.2434 & 43.94 \\
\hline GY & 5 & 1.4848 & 1.3516 & 0.1998 & 0.2897 & 48.48 \\
\hline MM & 5 & 1.4901 & 1.3273 & 0.1818 & 0.2604 & 40.91 \\
\hline YC & 3 & 1.4394 & 1.2753 & 0.1648 & 0.2460 & 43.94 \\
\hline mean & - & 1.4834 & 1.3115 & 0.1820 & 0.2689 & 47.19 \\
\hline
\end{tabular}

\subsection{Genetic structure of A. villosum populations}

Genetic structure information of $A$. villosum populations analyzed by Popgene 32 was shown in Table 5 . Total genetic diversity $(\mathrm{Ht})$ of the 7 populations was 0.3299 , while the within population genetic diversity was 0.1819 . Gene differentiation coefficient (Gst)was 0.4487 , indicating that $55.13 \%$ of the the genetic variation was existed withinpopulations. The result was similar to that of molecular variance analysis 
(AMOVA), which showing $68.74 \%(P=0.001)$ genetic variation was in within populations while $31.26 \%(P$ $=0.001)$ was between populations(Table 6$)$. Additionally, the gene flow $(\mathrm{Nm})$ among different populations was 0.4487 .

Table 5

Genetic structure of $A$. villosum

\begin{tabular}{|lllll|}
\hline $\begin{array}{l}\text { samples } \\
\text { size }\end{array}$ & $\begin{array}{l}\text { genetic diversity of the total } \\
\text { populations }(\mathrm{Ht})\end{array}$ & $\begin{array}{l}\text { genetic diversity within } \\
\text { populations }(\mathrm{Hs})\end{array}$ & $\begin{array}{l}\text { gene } \\
\text { differentiation } \\
\text { coefficient } \\
\text { (Gst) }\end{array}$ & $\begin{array}{l}\text { gene } \\
\text { flow } \\
(\mathrm{Nm})\end{array}$ \\
\hline 141 & 0.3299 & 0.1819 & 0.4487 & 0.6143 \\
\hline$\delta$ & 0.0272 & 0.0102 & & \\
\hline
\end{tabular}

Table 6

AMOVA analysis of $A$. villosum based on ISSR

\begin{tabular}{|lllllll|}
\hline $\begin{array}{l}\text { source of } \\
\text { variation }\end{array}$ & $\begin{array}{l}\text { degree of } \\
\text { freedom } \\
\text { /df }\end{array}$ & $\begin{array}{l}\text { mean } \\
\text { square } \\
\text { deviation } \\
\text { /SS }\end{array}$ & $\begin{array}{l}\text { mean } \\
\text { square } \\
\text { value } \\
\text { /MS }\end{array}$ & $\begin{array}{l}\text { variance } \\
\text { component }\end{array}$ & $\begin{array}{l}\text { variance } \\
\text { component } \\
\text { percentage (\%) }\end{array}$ & $P$ \\
\hline $\begin{array}{l}\text { among } \\
\text { populations }\end{array}$ & 6 & 167.835 & 27.972 & 3.718 & 31.26 & 0.001 \\
\hline $\begin{array}{l}\text { within } \\
\text { populations }\end{array}$ & 31 & 253.455 & 8.176 & 8.176 & 68.74 & 0.001 \\
\hline
\end{tabular}

\subsection{Genetic distance, genetic identity and cluster analysis}

Genetic distance and genetic identity are the main indicators to examine the degree of genetic differentiation and the relationship between groups [8]. The genetic distances of 7 populations were between 0.0844 and 0.3347 , and the genetic identity were between 0.7156 and 0.9191 (Table 7). Among them, the smallest genetic distance was between ZJD and TK population (0.0844), and the largest one wasbetween XFC and YC population (0.3347). Mantel test carried out with NTSYS-pc 2.0 indicated that the genetic distance and geographical distance were not significantly correlated $(r=0.02698, P=0.5504)$ (Fig. 6). 
Table 7

Genetic distance and genetic identity of $A$. villosum populations

\begin{tabular}{|llllllll|}
\hline & ZJD & TK & ZY & XFC & GY & MM & YC \\
\hline ZJD & $\star \star \star \star$ & 0.9191 & 0.9073 & 0.7908 & 0.7977 & 0.7569 & 0.7636 \\
\hline TK & 0.0844 & $\star \star \star \star$ & 0.8827 & 0.7177 & 0.7636 & 0.7538 & 0.7620 \\
\hline ZY & 0.0973 & 0.1247 & $\star \star \star *$ & 0.8222 & 0.8231 & 0.8011 & 0.8045 \\
\hline XFC & 0.2347 & 0.3317 & 0.1957 & $\star \star \star \star$ & 0.8639 & 0.7912 & 0.7156 \\
\hline GY & 0.2260 & 0.2697 & 0.1946 & 0.1463 & $\star \star \star \star$ & 0.8930 & 0.8182 \\
\hline MM & 0.2785 & 0.2827 & 0.2218 & 0.2342 & 0.1132 & $\star \star \star \star$ & 0.8709 \\
\hline YC & 0.2697 & 0.2719 & 0.2176 & 0.3347 & 0.2003 & 0.1382 & $\star \star \star *$ \\
\hline Note: Genetic identity above diagonal, genetic distance below diagonal \\
\hline
\end{tabular}

The UPGMA clustering map of populations based on genetic similarity coefficient was constructed using the data of Nei's genetic identity and genetic distance of 7 populations (Fig. 7). 7 populations were divided into three groups at the similarity coefficient of 0.84 . Three populations ZJD, TK and ZY formed one group. Three populationsGY, MM and YC formed another group. One population XFC formed a single group. The results of PCOA based on the unbiased pair Фst matrix of Nei were consistent with UPGMA cluster analysis(Fig. 8).

\section{Discussion}

In this study, five DNA barcodes ITS2, psbA-trnH, ITS, matK and $r b c L$ were amplified and sequenced from 141 individuals of $7 A$. villosum populations and finally 531 sequences were obtained. Thus a local DNA barcode reference library of $A$. villosum in its Daodi production area was constructed. Many DNA barcodes reference libraries have been constructed for the purpose of a more rapid and accurate species identification[9]. And DNA barcoding has been used in A. villosum identification [10-12].COI was an efficient species identification tool and frequently used in genetic diversity analysis of animals [13-17]. In plants, however, low substitution rates of mitochondrial DNA have made it unsuitable, and some other barcoding regions were searched as alternatives just like we used in the current study[18-20]. An ideal DNA barcode should be easily retrievable and bidirectionally sequenced, and provide maximal discrimination among species[21]. Among the five barcodes, the highest PCR amplification and sequencing success rate for $A$. villosum was $r b c L$. For a more comprehensive assessment of discrimination power of DNA barcodes, there needs more investigations of the DNA barcodes with adulterants of $A$. villosum included.

We aligned the sequences within the DNA barcodes, and no variation sites of the five barcodes were found. Therefore, genetic diversity could not be analyzed by these DNA barcodes. The main reason for Intra-specificdivergence could occur at a very high rate within geographically isolated populations[22]. But genetic diversity at the sub-specific level is best explored with a multi-locus approach such as 
fingerprinting techniques [23]. Consequently, we may say that ITS method ismore suitable for genetic diversity analyses of population with wide geographic areas[24].

For species identification, geographic structure and plant diversity of the populations might be the problems for the barcoding approach and these problems have to be dealt at the library construction stage[25]. Here, no polymorphisms were examined in any DNA barcode sequence indicating that these DNA barcodes were suitable for $A$. villosum identification. How much variation is actually needed to separate species is not known with certainty because intra-specific sampling has generally been limited to narrow geographic locales[26].

Molecular markers have been used extensively to determine genetic diversity and genetic relationships in plant science[27, 28]. Moradkhani etal.[29] expressed that the ISSR marker was used among marker systems as a desirable marker in a wide range of genetic variations in various plants. In the ISSR marker, most amplified fragments were between 200 and 1500 bp.

The richer the genetic diversity of species, the stronger the ability of species to adapt to the natural environment. The level of genetic diversity of plants can be influenced by a variety of factors, including the breeding system, the mechanism of seed transmission, geographical distribution, and natural selection[30]. The species with high genetic variation can resist the survival pressure caused by various environmental changes. The loss of genetic diversity will reduce the ability of species to adapt to environmental changes and affect the survival ability of species. Therefore, it is helpful to evaluate the genetic diversity level of $A$. villosum populations to analyze its evolutionary potential and provide reference for the identification, preservation and utilization of the germplasm resources of $A$. villosum. This provides a reference for increasing the genetic diversity and planting of $A$. villosum in different populations.

According to the ISSR markers, there was a high level of inter-population genetic variability and a relatively low level of genetic diversity within populations. Then we analyzed the genetic diversity and genetic structure of $A$. villosum populations by ISSR marker through the whole genome. Genetic diversity parameters indicated that the genetic diversity of germplasm materials of A.villosum in Yangchun was relatively rich (PPB $=47.19 \%, \mathrm{H}=0.1820, \mathrm{I}=0.2689)$. The results of Gst $(55.13 \%)$ and AMOVA $(68.74 \%)$ showed that more genetic variations existed in within populations.

Our results show that ISSR markers can effectively reveal the polymorphism among materials. Genetic diversity also differed somewhat within the 7 populations in this study. ISSR markers indicated that population ZY had the highest genetic diversity and TK had the lowest. This variation may be due to human activity, random genetic drift and/or inbreeding variation.

The higher the genetic differentiation index between populations, the more obvious the differentiation between populations and the more genetic difference between populations. Wright et al.[31]believed that the Gst value of genetic differentiation coefficient is between 0 and 0.05 , and the genetic differentiation of the populations is weak; between 0.05 and 0.15 , the genetic differentiation of the populations is moderate; 
between 0.15 and 0.25 , meaninga large genetic differentiation of the populations; when the Gst value is higher than 0.25 , the differentiation is extremely large. According to Nei's analysis of genetic diversity, the Gst value among $A$. villosum populations was 0.448 , which was greater than 0.25 , finding that the genetic differentiation between the populations was extremely large. AMOVA analysis showed that genetic variation within populations of $A$. villosum accounted for $68.74 \%(\mathrm{P}<0.05)$ of the total genetic variation in the populations, and genetic variation among populations accounted for $31.26 \%(P<0.05)$, indicating that most of the genetic variation of $A$. villosum occurred within the populations. Gene flow is the movement of genes within and between populations, and its intensity has an important effect on populations differentiation. In this study, the gene flow $\mathrm{Nm}$ between different populations was 0.6143 . According to Slatkin[32], the fraction of $\mathrm{Nm}>1$ between any population reflects that it is resistant to the influence of genetic drift, with sufficient communication and no obvious differentiation, so it can prevent populations segmentation. Therefore, the $\mathrm{Nm}$ value of 0.6143 indicated that genetic drift was the main factor affecting the genetic variation between populations and the genetic communication between populations is difficult, and high genetic variation was maintained within the population, which can be considered as an independent population. It was also confirmed by the genetic differentiation index between populations. The similarity and genetic relationship between plant populations can be expressed through genetic distance. Some scholars believe that genetic distance and geographic distance have a positive correlation[33]. While some scholars also believe that geographic distance and genetic distance are not significantly correlated[34].

The genetic distance of 7 populations was between 0.0844 and 0.3347 , and the genetic similarity coefficient was between 0.7156 and 0.9191 , indicating that the kinship of the populations was relatively close. If gene flow and seed transmission through the mating system are the main causes of populations variation, the closer the geographic distance between populations, the smaller the genetic differentiation. However, the result of the Mantel test indicated that the distribution of genetic diversity among populations may not be explained by obvious geographic distance and this results can be explained by enhancing the geographical distribution of gene flow, therefore, we can analyze the results through the grouping situation generated by the PCoA diagram and UPGMA. The populations in this study were clustered according to the similarity of habitats, regardless of geographic location, and populations with similar habitats are clustered together first, and 7 populations were clearly divided into three major clusters: ZJD, TK and ZY were clustered together, GY, MM and YC were clustered together, while XFC was a separate cluster. It could be an introduction problem. Isolates in different groups had a similarity range of $78-92 \%$, this high level of genetic diversity can be obtained through a series of evolutionary processes, including mutation, recombination and migration. The genetic level among populations was consistent with the results of PCoA and UPGMA cluster analysis revealed by ISSR markers.

In this study, ISSR marker technology is used to preliminarily analyze the genetic relationship of 7 populations by analysing band polymorphism, populations polymorphism, populations clustering based on genetic distance, populations genetic distance and genetic consistency, clustering result and PCoA, which can all verify that 7 populations have certain genetic diversity and ability to resist external invasion, which is undoubtedly a good news for the protection and cultivation of germplasm. It provides a 
theoretical basis for further research on the classification of $A$. villosum populations and lays a theoretical foundation for the protection and sustainable utilization of germplasm resources of Southern Medicine $A$. villosum.

\section{Materials And Methods}

\section{Plant Material Sampling}

A total of 141 samples of $A$. villosum were collected from 7 populations in Yangchun City, Guangdong Province from August to November 2018. The sampled plants were identified by Huang Zhihai, the chief Chinese pharmacist of the Second Clinical College of Guangzhou University of Chinese Medicine. Fresh and healthy leaves were moved from the plants, dried and preserved in silica gel right now in the field, thenstored in an ultra-low temperature refrigerator $\left(-80^{\circ} \mathrm{C}\right)$ when came back to the laboratory. Detailed information and geographic location of samples see Table 8 and Fig. 9.

Table 8

Sampling information of $A$. villosum from different populations in Guangdong Province

\begin{tabular}{|llllll|}
\hline No. & Pop. & Serial No. & longitude /N & $\begin{array}{l}\text { Latitude } \\
\text { /E }\end{array}$ & samples size \\
\hline 1 & ZhongjiaoDong & ZJD & $112^{\circ} 04^{\prime} 01^{\prime \prime}$ & $22^{\circ} 24^{\prime} 16^{\prime \prime}$ & 33 \\
\hline 2 & Tankui Village & TK & $112^{\circ} 04^{\prime} 30^{\prime \prime}$ & $22^{\circ} 24^{\prime} 22^{\prime \prime}$ & 16 \\
\hline 3 & G325 National Roadside, & ZY & $112^{\circ} 03^{\prime} 59^{\prime \prime}$ & $22^{\circ} 24^{\prime} 26^{\prime \prime}$ & 25 \\
\hline 4 & XingfuVillage, & XFC & $112^{\circ} 00^{\prime} 41^{\prime \prime}$ & $22^{\circ} 21^{\prime} 54^{\prime \prime}$ & 18 \\
\hline 5 & National Geopark, & GY & $111^{\circ} 49^{\prime} 51^{\prime \prime}$ & $22^{\circ} 35^{\prime} 19^{\prime \prime}$ & 19 \\
\hline 6 & Dianbai District, Maoming & $\mathrm{MM}$ & $111^{\circ} 12^{\prime} 21^{\prime \prime}$ & $21^{\circ} 45^{\prime} 52^{\prime \prime}$ & 10 \\
\hline 7 & Datong Village & $\mathrm{YC}$ & $111^{\circ} 58^{\prime} 48^{\prime \prime}$ & $22^{\circ} 23^{\prime} 25^{\prime \prime}$ & 20 \\
\hline
\end{tabular}

DNA extraction, PCR amplification and sequencing

The total DNA was extracted using Tiangen DP305 plant DNA kit method. The NanoDrop2000 ultra-micro ultriolet spectrophotometer was used to determine the DNA concentration and purity.

The PCR amplification reaction system of the experiment contained 2囚Taq PCR Mix $12.5 \mu \mathrm{L}$, forward primer $(2.5 \mu \mathrm{M}) 1.0 \mu \mathrm{L}$, reverse primer $(2.5 \mu \mathrm{M}) 1.0 \mu \mathrm{L}$, genomic DNA $2.0 \mu \mathrm{L}$ and added up to $25 \mu \mathrm{L}$ with $\mathrm{ddH}_{2} \mathrm{O}$. The primer sequences and amplification conditions of different DNA barcodes were shown in Table 9. All amplification reactions were completed on the ProFlex PCR instrument (Life Technologies, USA). PCR products were sent to Shanghai Meiji Biotechnology Company Guangzhou Branch to be sequenced. 
Table 9

Primers informations and PCR amplification conditions

\begin{tabular}{|c|c|c|c|}
\hline primers & & base(5'-3') & amplification conditions \\
\hline \multirow[t]{4}{*}{ ITS2 } & $2 \mathrm{~F}$ & ATGCGATACTTGGTGTGAAT & \multirow{4}{*}{$\begin{array}{l}94^{\circ} \mathrm{C}, 5 \mathrm{~min} \\
94^{\circ} \mathrm{C}, 30 \mathrm{~s} ; 56^{\circ} \mathrm{C} \varangle 30 \mathrm{~s} \otimes 72^{\circ} \mathrm{C} \varangle 45 \text { s. } 35 \\
\text { circles }\end{array}$} \\
\hline & & & \\
\hline & \multirow[t]{2}{*}{$3 R$} & \multirow[t]{2}{*}{ GACGCTTCTCCAGACTACAAT } & \\
\hline & & & \\
\hline \multirow{3}{*}{$\begin{array}{l}\text { psbA- } \\
\text { trnH }\end{array}$} & \multirow[t]{2}{*}{ fwd PA } & \multirow[t]{2}{*}{ GTTATGCATGAACGTAATGCTC } & $94^{\circ} \mathrm{C}, 4 \mathrm{~min}$ \\
\hline & & & $\begin{array}{l}94^{\circ} \mathrm{C}, 30 \mathrm{~s} ; 55^{\circ} \mathrm{C} \otimes 1 \mathrm{~min} \otimes 72^{\circ} \mathrm{C} \otimes 1 \mathrm{~min} . \quad 35 \\
\text { circles }\end{array}$ \\
\hline & rev $\mathrm{TH}$ & CGCGCATGGTGGATTCACAATCC & $72^{\circ} \mathrm{C}, 10 \mathrm{~min}$ \\
\hline \multirow[t]{4}{*}{ matK } & \multirow[t]{2}{*}{ 3F_KIM } & \multirow[t]{2}{*}{ CGTACAGTACTTTTGTGTTTACGAG } & $94^{\circ} \mathrm{C}, 1 \mathrm{~min}$ \\
\hline & & & $94^{\circ} \mathrm{C}, 30 \mathrm{~s} ; 52^{\circ} \mathrm{C} \varangle 20 \mathrm{~s} \otimes 72^{\circ} \mathrm{C} \varangle 50$ s. 35 \\
\hline & \multirow[t]{2}{*}{ 1R_KIM } & \multirow[t]{2}{*}{ ACCCAGTCCATCTGGAAATCTTGGTTC } & circles \\
\hline & & & $72^{\circ} \mathrm{C}, 5 \mathrm{~min}$ \\
\hline \multirow[t]{4}{*}{$r b c L$} & \multirow[t]{2}{*}{$1 \mathrm{~F}$} & \multirow[t]{2}{*}{ ATGTCACCACAAACAGAAAC } & $95^{\circ} \mathrm{C}, 4 \mathrm{~min}$ \\
\hline & & & $94^{\circ} \mathrm{C}, 1 \mathrm{~min} ; 55^{\circ} \mathrm{C} \otimes 1 \min \varangle 72^{\circ} \mathrm{C} \otimes 2 \min .38$ \\
\hline & \multirow[t]{2}{*}{$724 \mathrm{R}$} & \multirow[t]{2}{*}{ TCGCATGTACCTGCAGTAGC } & circles \\
\hline & & & $72^{\circ} \mathrm{C}, 7 \mathrm{~min}$ \\
\hline \multirow[t]{4}{*}{ ITS } & \multirow[t]{2}{*}{$5 F$} & \multirow[t]{2}{*}{ GGAAGTAAAAGTCGTAACAAGG } & $94^{\circ} \mathrm{C}, 5 \mathrm{~min}$ \\
\hline & & & $94^{\circ} \mathrm{C}, 1 \mathrm{~min} ; 50^{\circ} \mathrm{C} \otimes 1 \min \varangle 72^{\circ} \mathrm{C} \otimes 1 \min 30 \mathrm{~s}$. \\
\hline & \multirow[t]{2}{*}{$4 \mathrm{R}$} & \multirow[t]{2}{*}{ TCCTCCGCTTATTGATATGC } & 30 circles \\
\hline & & & $72^{\circ} \mathrm{C}, 7 \mathrm{~min}$ \\
\hline ISSR-P & R amplifi & tion system & \\
\hline
\end{tabular}

100 ISSR universal primer sequences published by Columbia University were screened[35]. And 6 primers that produced clear and reproducible banding patterns were selected (Table 5). ISSR-PCR amplifications were performed on 141 individuals from $7 \mathrm{~A}$. villosum populations using the selected primers in a $20 \mu \mathrm{L}$ reaction volume including $10 \mu \mathrm{L} 2 \mathrm{X}$ PCR Mix (containing dye, $\mathrm{MgCl}_{2}$, dNTPs), $2 \mu \mathrm{L}$ template DNA, $1 \mu \mathrm{LISSR}$ primer and $7 \mu \mathrm{L} \mathrm{ddH_{2 }} \mathrm{O}$. The ISSRPCR amplification procedures were programmed in the ProFlexrmocycler as follows: predenaturation at $94^{\circ} \mathrm{C}$ for $5 \mathrm{~min}, 35$ cycles of denaturation at $94{ }^{\circ} \mathrm{C}$ for $45 \mathrm{~s}$, annealing at the $\mathrm{Tm}$ value of the primer for $45 \mathrm{~s}$, extension at $72{ }^{\circ} \mathrm{C}$ for $2 \mathrm{~min}$, with a final extension at $72{ }^{\circ} \mathrm{C}$ for 5 minand preservation at $4{ }^{\circ} \mathrm{C}$. ISSR-PCR products were separated on a $2 \%$ agarose gel stained with Goldview by electrophoresis in $1 \times$ TAE buffer at $80 \mathrm{~V}$. The gels were visualized under UV light and photographed with Bio-Rad ChemiDoc imagingsystem (USA). The molecular weights of ISSR-PCR products were estimated using a 100 bp Plus DNA Ladder (TIANGEN Biotech Co., Ltd., Beijing, China). 


\section{Data analysis}

The two-way sequenced peaks of DNA barcodes were evaluated and assembled by CondonCode Aligner v8.0.1 software. Low-quality areas at both ends of the assembled sequences were removed. ITS2 barcodes were annotated by cutting off the conserved $5.8 \mathrm{~S}$ and $28 \mathrm{~S}$ motifs based on HMM[23] and the ITS2 database[24]. Mega6.0 software was used to align DNA barcode sequences and calculate sequence statistics including the base composition ratio, GC content, heterotopic site information, conservative site and parsimony informative sites. Haplotype sequences for each barcodes were exhibited in the twodimensional code picture. In the picture, each vertical line represented a base, and the two-dimensional code on the right could be scanned directly read the DNA sequence.

Reproducible ISSR-PCR bands weredetermined with the help of the GelPro32 software and manual correction. These clear bands were scored as either present (1) or absent (0), thus generating an ISSR phenotype data matrix. And the data matrix was imported in Popgene32 software to analyze genetic diversity and genetic structure. Genetic diversity parameters included percentage of polymorphic sites (PPB), number of alleles ( $\mathrm{Na}$ ), effective number of alleles $(\mathrm{Ne})$, Nei's gene diversity index $(\mathrm{H})$ and Shannon's polymorphism information index (I) were calculated. Genetic structure parameters included Nei's gene differentiation coefficient (Gst), total population genetic diversity $(\mathrm{Ht})$, intra-group genetic diversity $(\mathrm{Hs})$ and gene flow $(\mathrm{Nm})$ were calculated. GenAlEx 6.502 software was used to estimate the components of genetic variance within and among populations by analysis of molecular variance (AMOVA) and to assess the correlation between population genetic distance and geographic distance byMantel tests. Genetic distance and genetic similarity coefficient among populations were calculated and a UPGMA dendrogram was constructed by using NTSYS $2.10 \mathrm{e}$.

\section{Conclusion}

A total of 141 samples of $A$. villosum from 7 populations in Guangdong Province were used to construct a reference DNA barcode reference library containing 531 sequences. On the anther hand, the 7 populations were significantly grouped in the cluster analysis and the genetic level of each population from high to low was as follow: $Z Y>Z J D>G Y>M M>Y C>X F C>T K$. Based on the above research results, the following planting recommendations for $A$. villosum are proposed: priority should be given to the populations ZY, ZJD and GY with rich genetic diversity, in order to preserve as much genetic diversity as possible. At the same time, considering the significant genetic differentiation between A. villosum, in-situ conservation should be stepped up for every existing population, and it is recommended to add a protected area in Yangchun City.

A high level of genetic diversity is very important for the long-term survival of the species. A. villosum, which is used for both medicine and food from Zingiberaceae, has a very narrow distribution range due to its special requirements for the growth environment. This study found that the genetic diversity of $A$. villosum is relatively rich. It also confirms from the molecular level that the Yangchun area is the origin of A. villosum. But currently, A. villosum is facing many problems such as high incidence of pests and 
diseases, unstable yield, lack of cultivation management, difficulty in breeding seedlings, and so on. Based on the results of this research, establish a germplasm resource nursery for A. villosum, extensively collect germplasm resources, and carry out research on excellent germplasm selection, seedling breeding, and high-yield and high-quality cultivation techniques of $A$. villosum, which is crucial to the protection and utilization resources of $A$. villosum.

\section{Declarations}

\section{Ethics approval and consent to participate: Not applicable.}

Consent for publication:The authors agree to publish this research.

Availability of data and materials:The extracted features datasets used and/or analyzed during the current study are available from the corresponding author on reasonable request. All the other data generated or analyzed during this study are included in this article.

Competing of interests: The authors declare that the research was conducted in the absence of any commercial or financial relationships that could be construed as a potential conflict of interest.

Funding: This work was supported by project 20184013, Demonstration Research on precise powder decoction pieces in traditional Chinese Medicine from Traditional Chinese Medicine Bureau of Guangdong Province of China; 002009,Quality standard system construction for the whole industry chain of Chinese medicinal decoction pieces from Guangdong Provincial Drug Administration of China.

Author's contributions: Conceptualization, Zhihai Huang; methodology, XiaohuiQiu.; software, He Su; validation, Wan Guan; formal analysis, Danchun Zhang; investigation, Lu Gong; resources, Zhihai Huang; data curation, Zhihai Huang; writing-original draft preparation, Danchun Zhang; writing-review and editing, Xiaoxia Ding; visualization, He Su; supervision, Zhihai Huang and Juan Huang; project administration, Zhihai Huang; funding acquisition, Zhihai Huang. All authors have read and agreed to the published version of the manuscript.

Acknowledgements:Thanks to the experimental platform of Guangdong Provincial Hospital of Chinese Medicine and Guangdong Provincial Key Laboratory of Clinical Research on Traditional Chinese Medicine Syndrome and funders.

\section{References}

1. Therapeutic Effect of Amomum villosum on Inflammatory Bowel Disease in Rats. Frontiers in Pharmacology 2018, 9.

2. Zhanhuan, S. RESEARCH MEANS OF GENETIC DIVERSITY AND ITS PROTECTIVE MEASURES. Journal of Ningxia Agricultural College 2002. 
3. Jun, P.; Fuyao, Z.; Xin, L.; Zhihong, D.; Huiming, L.; Zhaoxiang, T.; Tingting, Y. A Review of DNA Molecular Markers and Its Application in Sorghum Breeding. chinese agricultural science bulletin 2011.

4. Souframanien, J.; Gopalakrishna, T. A comparative analysis of genetic diversity in blackgram genotypes using RAPD and ISSR markers. Theoretical and Applied Genetics 2004, 109.

5. A., L.; E., T.; T., J.; X., Z.; A., D. A genetic linkage map for watermelon derived from a testcross population: ( Citrullus lanatus var. citroides $\times \mathrm{C}$. lanatus var. lanatus) $\times$ Citrullus colocynthis. TAG. Theoretical and applied genetics. Theoretische und angewandte Genetik 2002, 105.

6. S, A.A.L.; P, C.P.; A, M.M.; P, d.P.C.M.; S, S.F. High degree of genetic diversity among genotypes of the forage grass Brachiaria ruziziensis (Poaceae) detected with ISSR markers. Genetics and molecular research : GMR 2011, 10.

7. Shilin, C.; Xiaohui, P.; Hui, Y.; Jianping, H.; Kun, L. Identification System and Perspective for DNA Barcoding Traditional Chinese Materia Medica. World ence \& Technology 2011.

8. Poyraz; Ismail. Comparison of ITS, RAPD and ISSR from DNA-based genetic diversity techniques. Comptes Rendus Biologies 2016.

9. Lou, S.K.; Wong, K.L.; Li, M.; But, P.H.; Tsui, K.W.; Shaw, P.C. An integrated web medicinal materials DNA database: MMDBD (Medicinal Materials DNA Barcode Database). Bmc Genomics 2010, 11, 402.

10. Shu, W.J.; Fen, Y.J.; Ting, Z.R.; Pharmacy, S.O. Identification of Amomum villosum Lour. and Its Adulterants Based on rbcL Gene. Lishizhen Medicine and Materia Medica Research 2018.

11. Jian-Ping, H.; Mei-Ni, L.I.; Lin-Chun, S. Identification of Amomi fructus and its adulterants based on ITS2 sequences. Global Traditional Chinese Medicine 2011.

12. Gui-Fang, Z.; Zhi-Min, Z.; Song, H.; Xiao-Ping, L. Identification and Clustering Analysis of Zingiberaceae with matK Barcode. Lishizhen Medicine and Materia Medica Research 2018.

13. Xin, C. PERSPECTIVE OF MOLECULAR BIOLOGICAL TECHNIQUES APPLIED IN INSECT SYSTEMATICS. Acta Zootaxonomica Sinica 2000.

14. Hebert, P.D.N.; Ratnasingham, S.; De Waard, J.R. Barcoding animal life: cytochrome c oxidase subunit 1 divergences among closely related species. Proc Biol 2003, 270, S96.

15. Heng-Guo, H.E. Application of Molecular Marker Techniques in Insect Population Genetics. Journal of China West Normal University(Natural ences) 2008.

16. Mitochondrial DNA Indicates Late Pleistocene Divergence of Populations of Heteronympha merope, an Emerging Model in Environmental Change Biology. Plos One 2009, 4, e7950.

17. Ye, F.Y.; Zhu, C.D.; Yefremova, Z.; Liu, W.X.; Guo, J.Y.; Wan, F.H. Life history and biocontrol potential of the first female-producing parthenogenetic species of Diglyphus (Hymenoptera: Eulophidae) against agromyzid leafminers. Scientific Reports 2018, 8, 3222.

18. Vere, N.D.; Rich, T.C.G.; Trinder, S.A.; Long, C. DNA Barcoding for Plants. Methods in Molecular Biology 2015, 1245, 101-118. 
19. Kress, W.J.; Wurdack, K.J.; Zimmer, E.A.; Weigt, L.A.; Janzen, D.H. Use of DNA barcodes to identify flowering plants. Proceedings of the National Academy of Sciences 2005, 102, 8369-8374.

20. Hollingsworth, M.L.; Clark, A.A.; Forrest, L.L.; Richardson, J.; Pennington, R.T.; Long, D.G.; Cowan, R.; Chase, M.W.; Gaudeul, M.; Hollingsworth, P.M. Selecting barcoding loci for plants: evaluation of seven candidate loci with species-level sampling in three divergent groups of land plants. Molecular Ecology Resources 2010, 9, 439-457.

21. Hollingsworth, P.M.; Forrest, L.L.; Spouge, J.L.; Hajibabaei, M.; Little, D.P. A DNA barcode for land plants. Proceedings of the National Academy of ences 2009, 106, 12794-12797.

22. Hebert, P.D.N.; Ryan, G.T. The promise of DNA barcoding for taxonomy. Systematic Biology 2005, 852859.

23. Keller, A.; Schleicher, T.; Schultz, J.R.; Müller, T.; Dandekar, T.; Wolf, M. 5.8S-28S rRNA interaction and HMM-based ITS2 annotation. Gene 2009, 430, 50-57.

24. Ankenbrand, M.J.; Alexander, K.; Matthias, W.; Jörg, S.; Frank, F. ITS2 Database V: Twice as Much. Molecular Biology \& Evolution, 3030.

25. Sarwat, M. DNA barcoding, microarrays and next generation sequencing: recent tools for genetic diversity estimation and authentication of medicinal plants: Critical Reviews in Biotechnology: Vol 36, No 2. Critical Reviews in Biotechnology 2014.

26. Phillips, J.D.; Gillis, D.J.; Hanner, R.H. Incomplete estimates of genetic diversity within species: Implications for DNA barcoding. Ecology and Evolution 2019.

27. Wei, X.; Mingfang, Z.; Guixia, J.; Xuqing, C.; Qian, W.; Xiuhai, Z.; Ran, D.; University, J.A. ISSR Analysis on Genetic Diversity of Lily Varieties with Different Hybrid Lines. Molecular Plant Breeding 2019.

28. Hai, H. The Application of Molecular Marker Technique to the Studies of Germplasm Resources of Dendrobium. Biotechnology Bulletin 2010.

29. Moradkhani, H.; Mehrabi, A.A.; Etminan, A.; Pour-Aboughadareh, A. Molecular diversity and phylogeny of Triticum-Aegilops species possessing D genome revealed by SSR and ISSR markers. 2015.

30. Yu; Ye-Bing; Guo; Qiao-Sheng; Zhao; Wei-Hong; Zhang; Ming-Ming; Shen; Wen-Biao. Analysis of the genetic diversity and population structure of Perinereis aibuhitensis in China using TRAP and AFLP markers. Biochemical Systematics and Ecology 2015.

31. Evolution and the Genetics of Populations. 4: Variability within and among natural populations: By S. Wright. 1978. Chicago \& London: The University of Chicago Press. A vol. in- $8 \hat{A}^{\circ}, x+582$ pp., figs, tabs, bibl., index. Bound Â£26.25. Academic Press 1980, 9.

32. Slatkin. Gene flow and the geographic structure of natural populations. Ence 1987, 236, 787-792.

33. Jinxing, M.A.; Zhuanzhuan, Y.; Jiyu, Z.; Qisheng, F.; Tiemei, W.; Xinshi, L.U.; University, B.F. Analysis of Genetic Diversity of 20 wild Alfalfa Germplasms in Xinjiang with RAPD and ISSR Markers. Journal of Yunnan Agricultural University(Natural ence) 2018.

34. Qiao-Yan, X.; Xi-Yang, H.; Hong, L.I.; Shui-Yuan, J. ISSR Analysis on Genetic Diversity of Medically Important Zanthoxylum nitidum(Roxb.)DC.in Guangxi. Guangxi ences 2014. 


\section{Figures}

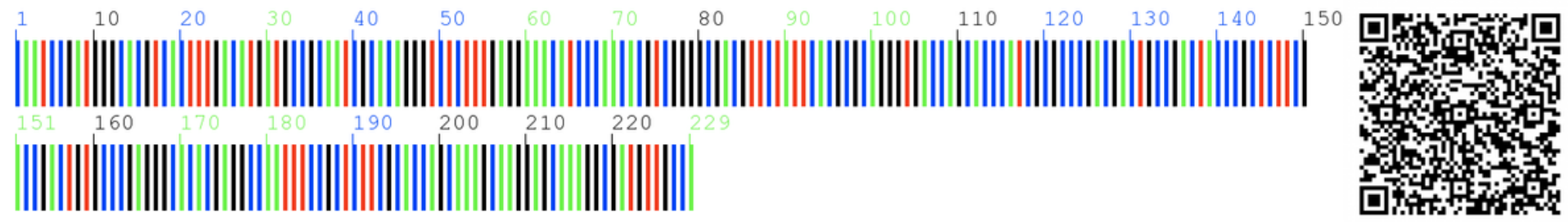

Figure 1

ITS2 sequence of A. villosum

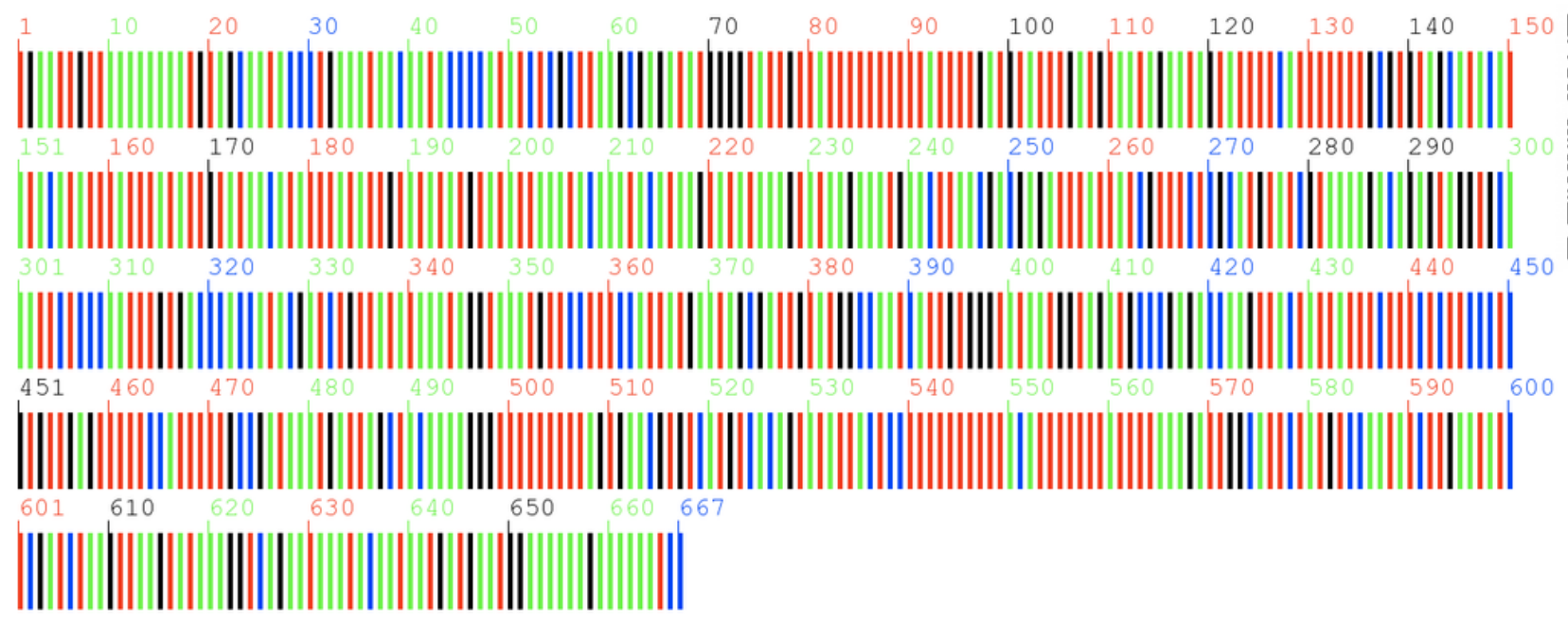

Figure 2

psbA-trnH sequence of A. villosum

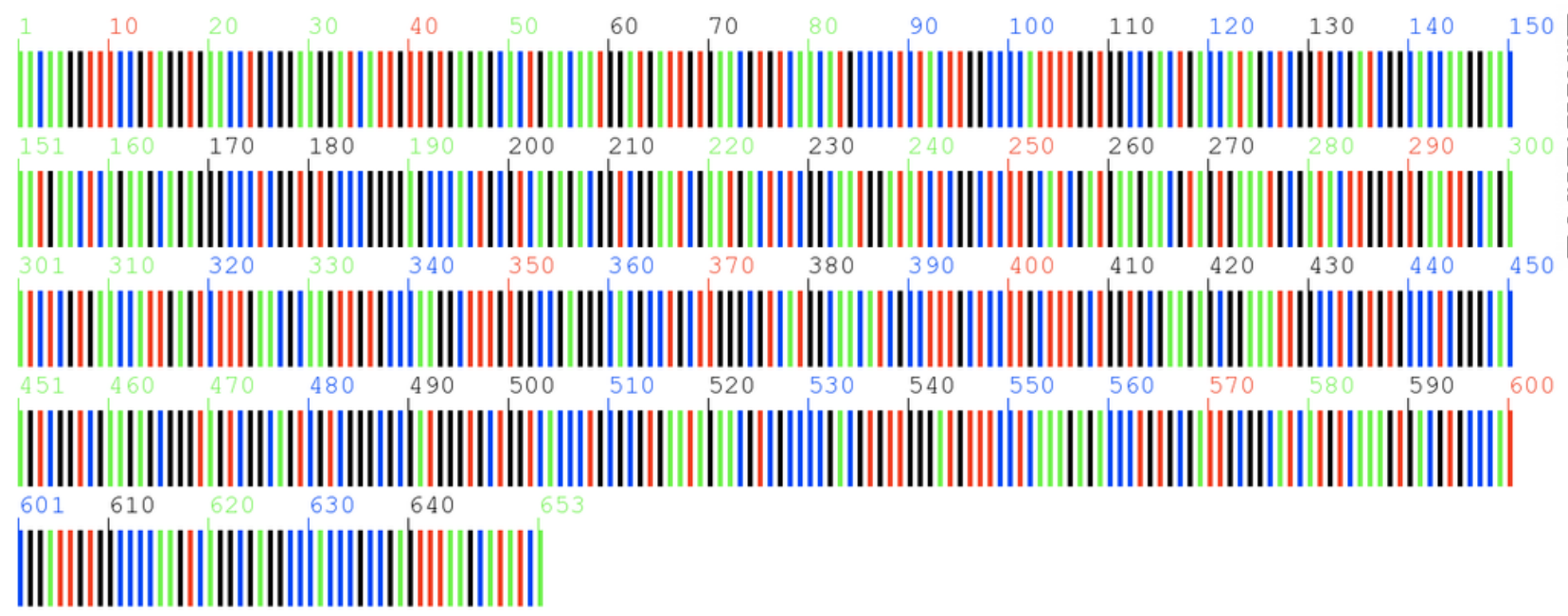

Figure 3 
ITS sequence of $A$. villosum

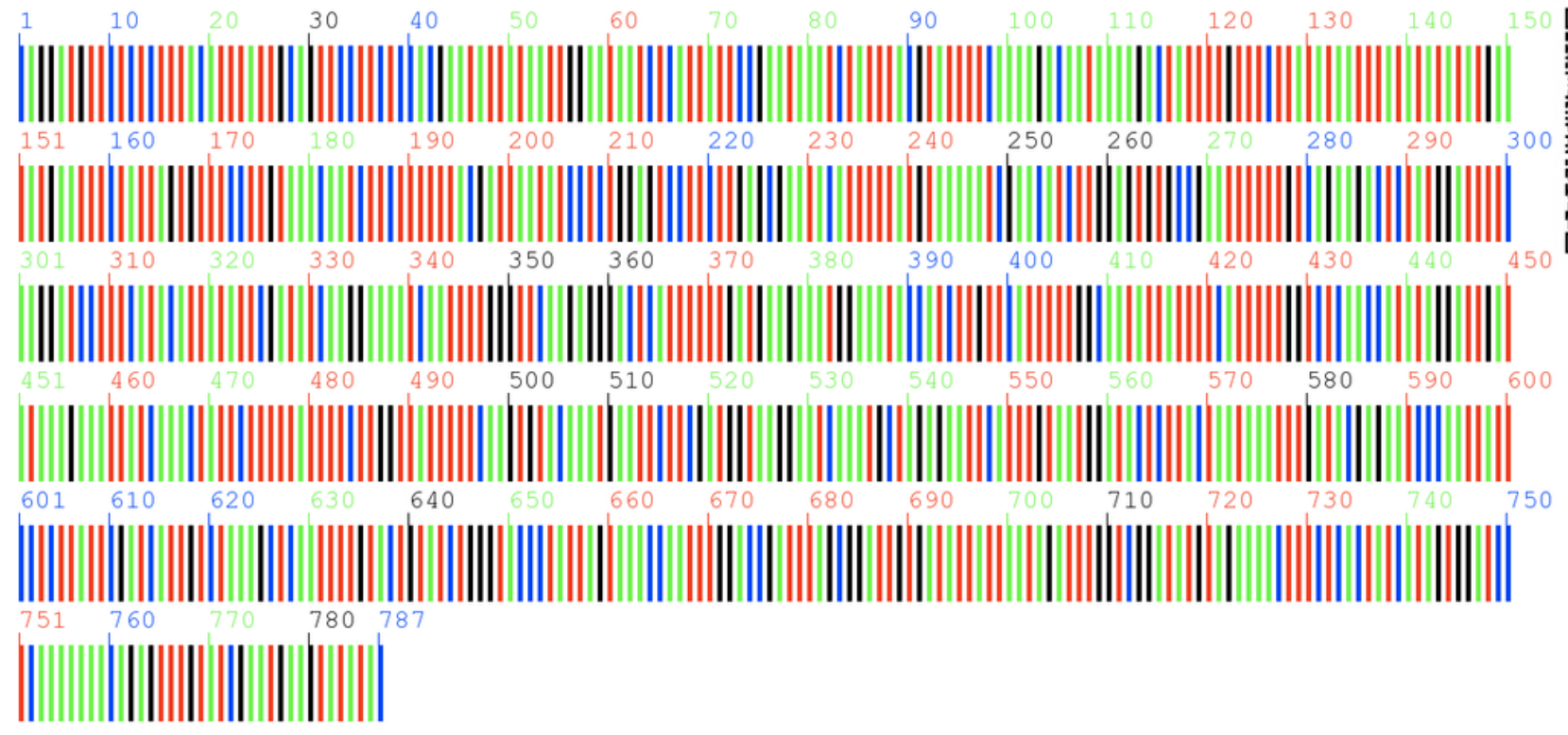

Figure 4

matK sequence of $A$. villosum

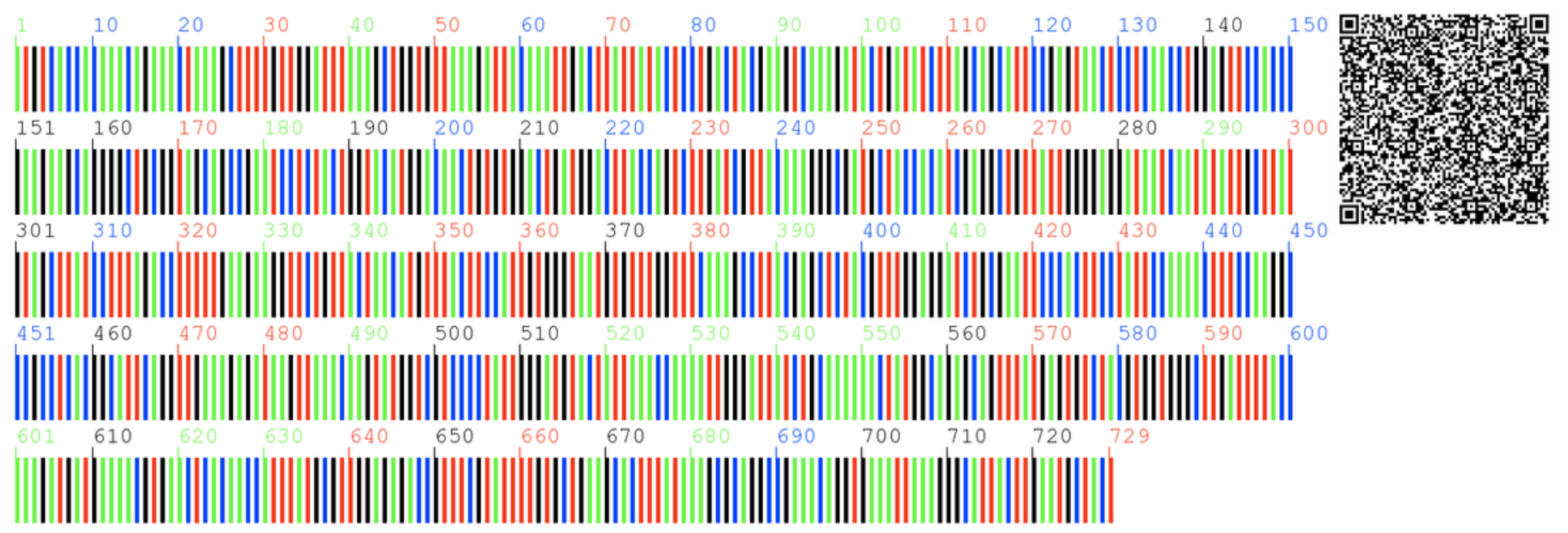

Figure 5

rbcL sequence of $A$. villosum 


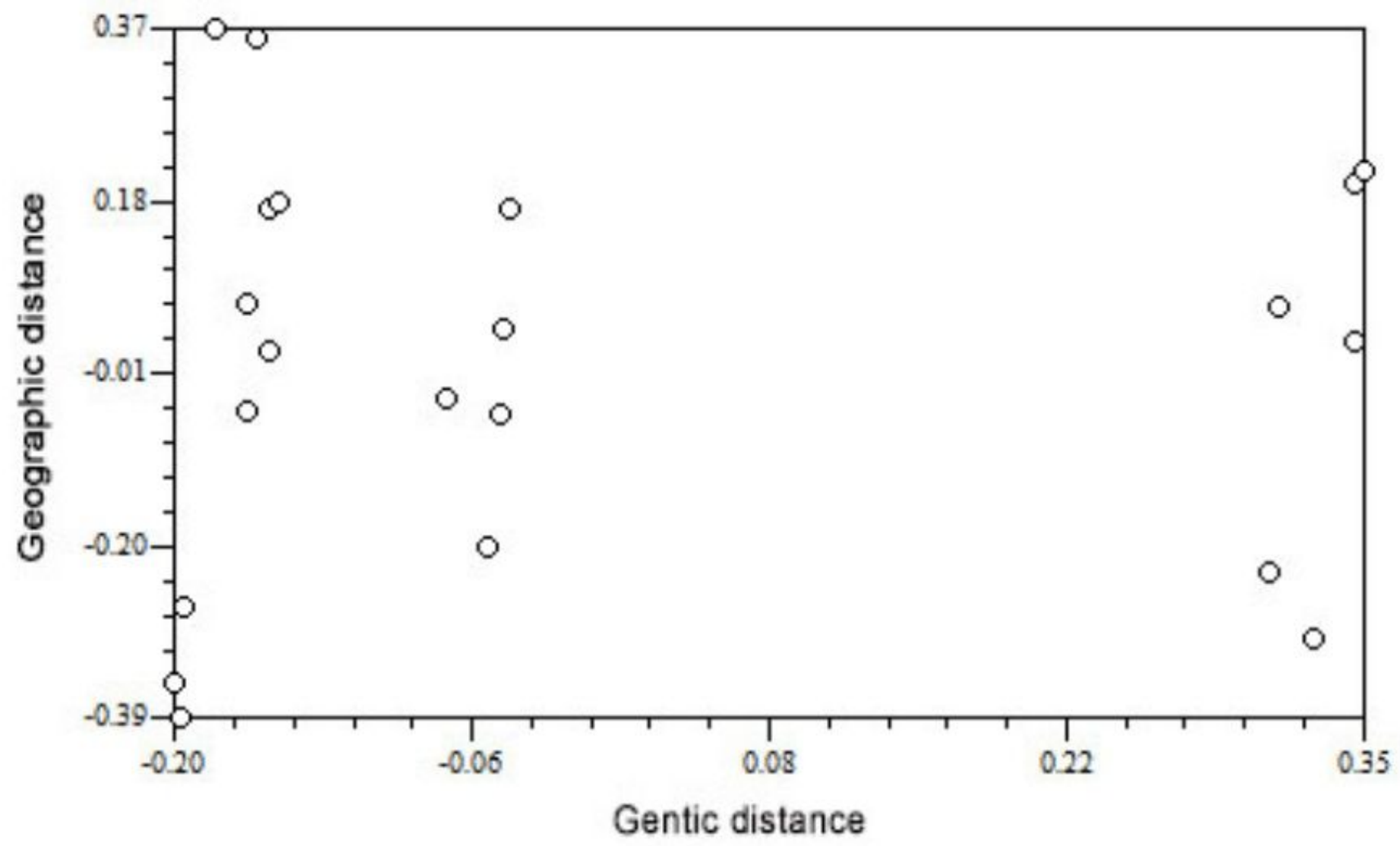

Figure 6

Correlation of geographic distance and genetic distance 


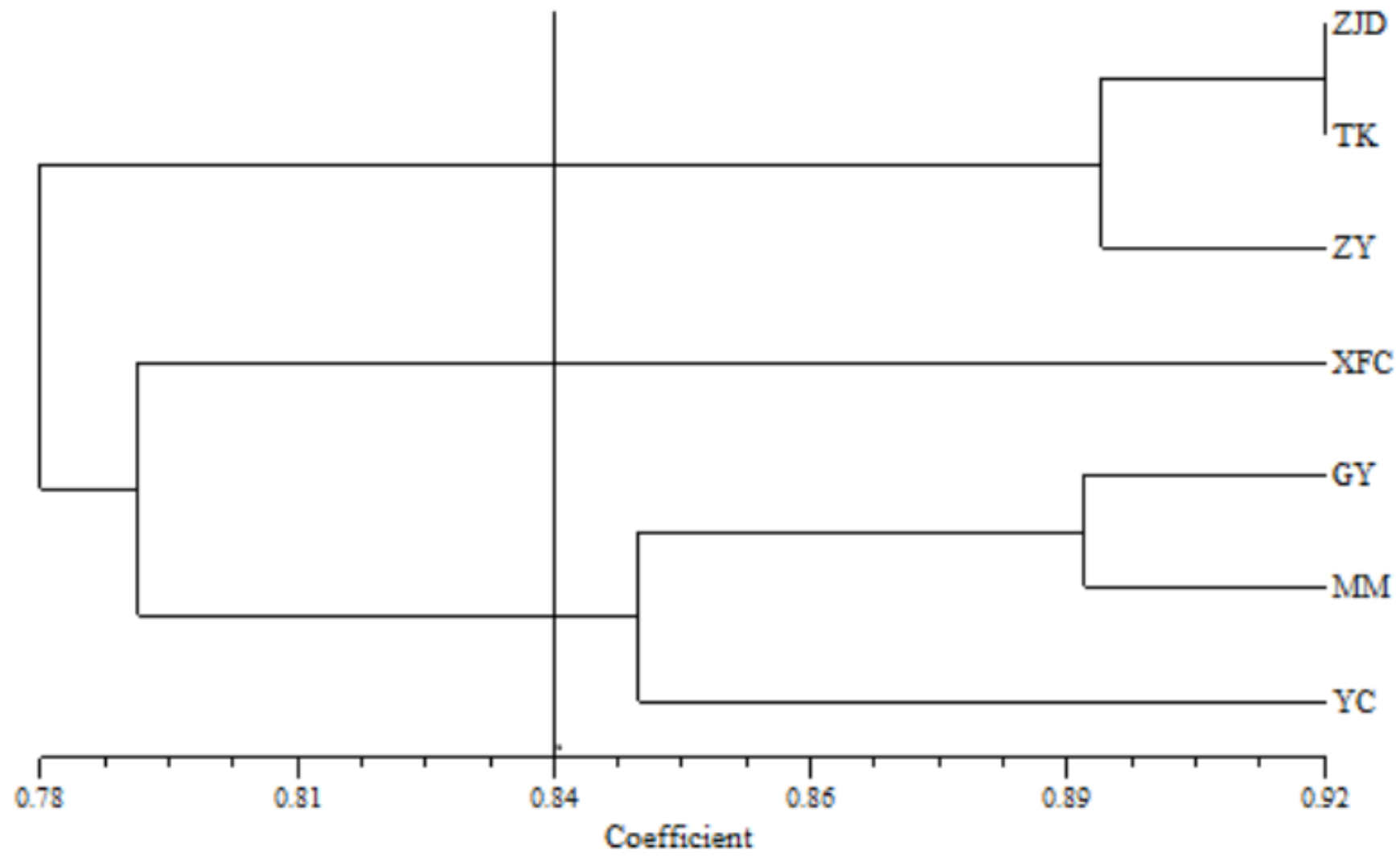

Figure 7

UPGMA clustering map of A. villosum

Principal Coordinates (PCoA)

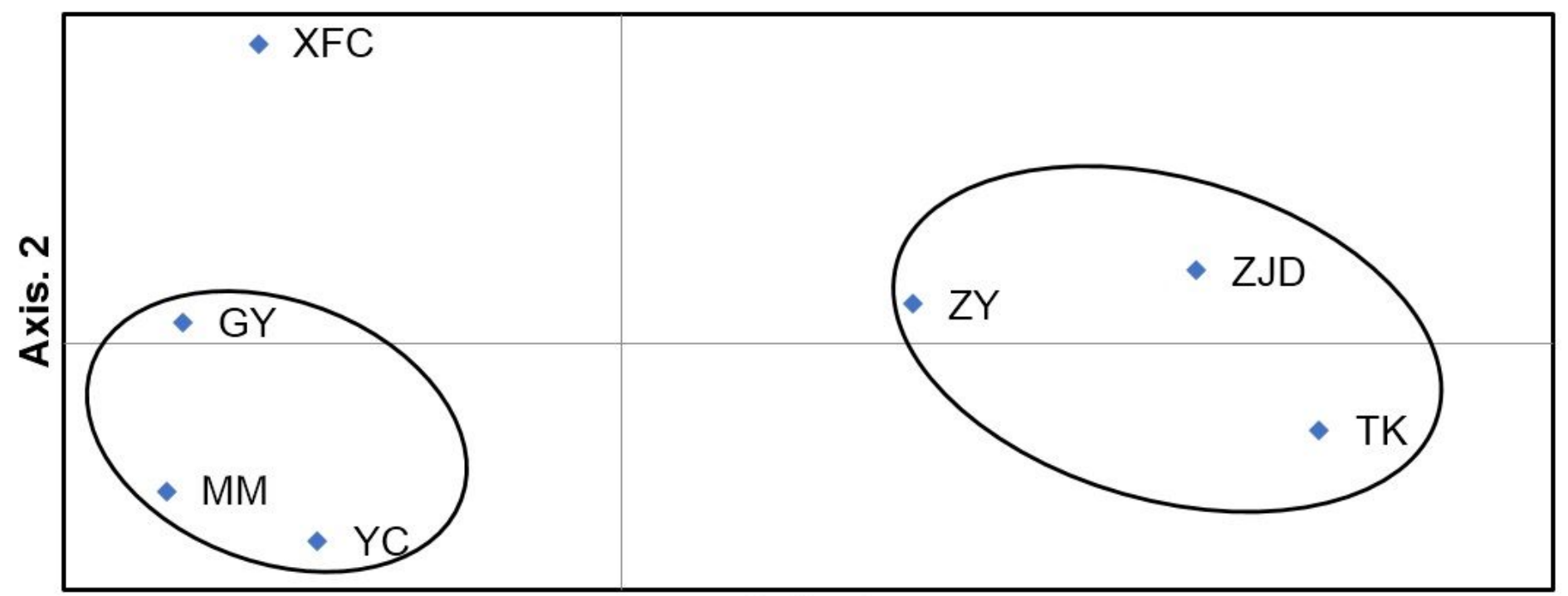

Axis. 1

Figure 8 
PCoA map of A. villosum based on ISSR molecular markers (coord. $1=48.04 \%$ and coord. $2=26.74 \%$ )

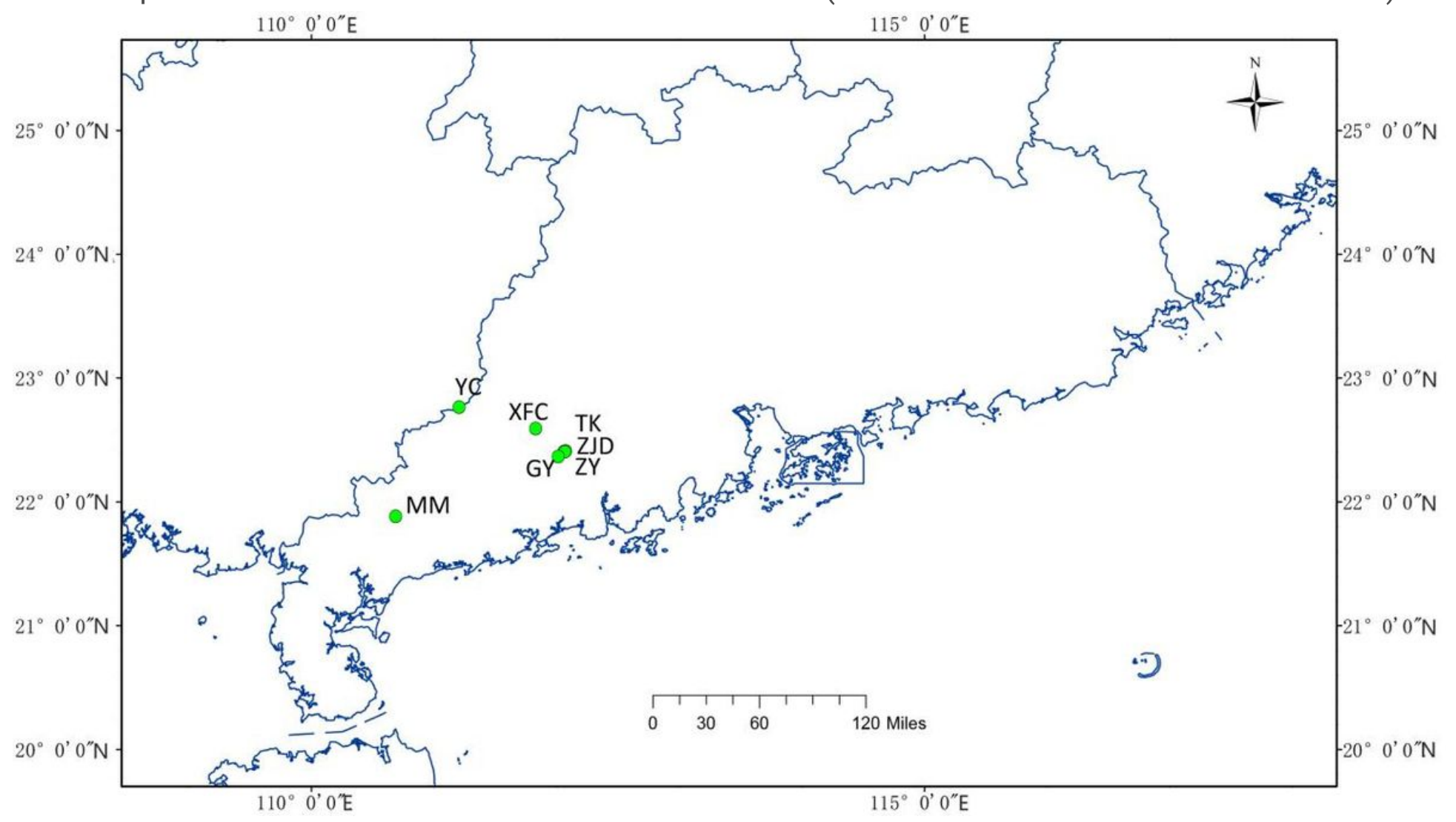

Figure 9

Geographical distribution of collected A. villosum populations. Note: The designations employed and the presentation of the material on this map do not imply the expression of any opinion whatsoever on the part of Research Square concerning the legal status of any country, territory, city or area or of its authorities, or concerning the delimitation of its frontiers or boundaries. This map has been provided by the authors.

\section{Supplementary Files}

This is a list of supplementary files associated with this preprint. Click to download.

- supplementarymaterial.rar 